\title{
Simuliidae (Diptera:Culicomorpha) no Brasil XI - Shelleyellum gênero novo
}

\author{
Victor PY-DANIEL ${ }^{1}$, Felipe Arley Costa PESSOA $^{1}$
}

\section{RESUMO}

É caracterizado um novo gênero neotropical de simulídeo, com base nas espécies previamente incluídas no "Grupo Siolii", do gênero Psaroniocompsa. Chaves de identificação para imaturos são apresentadas. O gênero Shelleyellum fica constituído pelas espécies: S. damascenoi (Py-Daniel,1988), S. guaporense (Py-Daniel, 1989), S. lourencoi (Py-Daniel, 1988), S. siolli (Py-Daniel, 1988), S. tergospinosum (Hamada, 2000). O gênero é caracterizado, principalmente, pela de carena longitudinal nos distímeros dos machos e a presença de tubérculos tegumentares nas larvas.

\section{PALAVRAS-CHAVE}

Shelleyellum gen. nov., taxonomia, Simuliidae, Neotrópico

\section{Brazilian Simuliidae (Diptera:Culicomorpha) $X I$ - Shelleyellum new genus}

\begin{abstract}
Anew neotropical genus of simuliids is characterized based on species previously included in the "Siolii Group" of Psaroniocompsa genus. Identifications keys for immature stages are presented. Shelleyellum genus is constituted by the species: S. damascenoi (PyDaniel,1988), S. guaporense (Py-Daniel, 1989), S. lourencoi (Py-Daniel, 1988), S. siolli (Py-Daniel, 1988), S. tergospinosum (Hamada, 2000). The genus is mainly characterized by longitudinal carina in male distimere and the presence of tegumentary tubercles in the larvae.
\end{abstract}

\section{KEYWORDS}

Shelleyellum n. gen., taxonomy, Simuliidae, Neotropics

${ }^{1}$ Laboratório de Filarioses e Vetores, Coordenação de Pesquisas em Ciências da Saúde, Instituto Nacional de Pesquisas da Amazônia, C.P. 478, 69011-970, Manaus, AM, Brasil, telefone +559236433232 E-mail: pydaniel@inpa.gov.br, pessoa@inpa.gov.br 


\section{ACTA AMAZONICA}

SIMULIIDAE (DIPTERA:CULICOMORPHA) NO BRASIL $\mathrm{XI}$ - Shelleyellum GÊNERO NOVO

\section{INTRODUÇÃO}

Py-Daniel (1983) caracterizou dois gêneros, originalmente descritos como subgêneros, próximos de Psaroniocompsa: Cerqueirellum e Coscaroniellum. Crosskey \& Howard (1997, 2004) mesmo sem fazerem estudos das relações filogenéticas, consideraram como grupos de espécies dentro de Psaroniocompsa, no qual, Coscarón \& Wygodzinsky (1984) e Coscarón (1987) tinham definido apenas 14 espécies.

Crosskey \& Howard (1997; 2004), ao ampliarem a diagnose de Psaroniocompsa, incluíram 41 espécies em cinco grupos e algumas espécies não agrupadas, fazendo com que este gênero, considerado por eles como subgênero de Simulium, assumisse uma posição imprópria, com base em muitas espécies não relacionadas, ou seja, o inverso do que aos poucos deixa de acontecer com o gênero Simulium: Py-Daniel \& Moreira Sampaio (1994), com base em estudos filogenéticos, sugeriram que Simulium, não fosse assinalado para a maior parte da região Neotropical, ficando mais representado nas regiões Holoártica; Coscarón et al. (1999), também com base em estudos filogenéticos, ao revisarem Simulium (Simulium) para a região Neotropical sugerem que as espécies assinaladas dentro deste táxon deveriam ser colocadas sob um outro nome, Aspatbia Enderlein, 1935, concordando com Py-Daniel \& Moreira Sampaio (1994). Adler et al. (2004) aceitaram a proposta de PyDaniel \& Moreira Sampaio (1994), reforçada por Coscarón et al. (1999) e usaram Aspathia, que Crosskey \& Howard colocaram dentro de Simulium, para as espécies neotropicais.

Py-Daniel (1988) descreveu as espécies siolii, lourencoi, e damascenoi e as colocou em Psaroniocompsa, enquanto não fossem conhecidos os machos de damascenoi e os imagos de lourencoi. Py-Daniel (1989) descreveu guaporense e agregou esta espécie junto com as anteriores, ao que denominou "Grupo Siolii", dentro de Psaroniocompsa. Coscarón \& Coscarón-Árias (1997) ao fazerem uma análise cladística, onde incluíram Psaroniocompsa, demonstraram que o "Grupo Siolii" se apresentava diferenciado das outras espécies de Psaroniocompsa. Hamada (2000) descreveu tergospinosum incluindo a espécie em Psaroniocompsa, no Grupo Siolii. Hamada \& Azevedo (2002) descreveram o macho de lourenco $i$ e Hamada et al. (2003) descreveram o macho de damascenoi. Pessoa (2004), em uma revisão filogenética dos gêneros Cerqueirellum e Coscaroniellum, utilizou algumas espécies de Psaroniocompsa, incluindo as espécies do Grupo Siolii, nos grupos internos analisados, e não encontrou uma monofilia entre o grupo Siolii e outras espécies de Psaroniocompsa, sendo obtido um cladograma, bem definido e consistente, para o grupo, reforçando, em detalhes, a posição deste grupo Siolii diferenciada das espécies do gênero Psaroniocompsa conforme demonstrado por Coscarón \& Coscarón-Arias (1997). Em trabalho subseqüente serão apresentadas as relações filogenéticas de Shelleyellum com os gêneros Cerqueirellum, Coscaroniellum ePsaroniocompsa.

\section{MATERIAL E MÉTODOS}

Todo o material entomológico utilizado neste estudo, se encontra depositado na Coleção de Invertebrados do INPA (Simuliidae). Foram utilizadas apenas as descrições na literatura quando os tipos não estavam disponíveis. Para o estudo morfológico foi seguida a metodologia e a nomenclatura das estruturas anatômicas usada pela maioria dos autores que trabalham em taxonomia de Simuliidae.

As estruturas morfológicas apresentadas neste artigo foram obtidas diretamente de um sistema de imagens sinópticas, com uma câmera digital JVC, modelo KY-F5 5 BE, acoplada a um microscópio composto Leica DMLB e conectado a um computador com o programa Auto Montage 4.0 (Syncroscopy) do Laboratório da Biodiversidade, Centro de Pesquisas Leônidas e Maria Deane / FIOCRUZ-AM. As imagens obtidas e digitalizadas foram gravadas em CDs e depositadas na Coleção de Simuliidae do INPA.

\section{RESULTADOS E DISCUSSÃO}

\section{Shelleyellum nov. gen.}

Diagnose dos Semaforontes: ADULTOS - Espécimes pequenos, de 1,3 até 2,0 $\mathrm{mm}$. Fêmeas: Cabeça com fronte isométrica ou subisométrica; triângulos fronto-oculares nas fêmeas reduzidos, Suturas infra-frontais curtas (Fig. 1a-b). Altura da área fronto-ocular menor que o dobro da largura do mesmo. Abertura proximal da concavidade da parte central do cibário nitidamente mais larga que o fundo distal, que tem dentes rombos e com porção basilar interna dos braços laterais do cibário com duas a três fileiras de dentes agudos subtriangulares; laterais à concavidade central; dentículos infradistais (Pessoa, 2004) na parte central do cibário ausentes (Fig. 1f-g). Mesonoto das fêmeas enegrecido, com luz incidindo frontalmente aparecem 1+1 manchas dorsais triangulares pruinosas, que se estendem desde a região anterior até a posterior, reduzindo a largura no sentido antero-posterior; com luz lateral, aparece mais nitidamente, uma faixa larga pruinosa que circunda lateral e posteriormente o mesonoto. Fêmures e tíbias de todas as pernas apresentando escamas espatuliformes entremeadas com setas filiformes. Calcípala e pedisulco bem desenvolvidos, garras tarsais sem dentículos sub-basilares (Fig. 1h-i); abdome com cercos arredondados, paraproctos curtos, gonapófises subtriangulares (Fig. 2a-b), com esclerotizações nas margens internas e com microtríquias que não atingem as margens das mesmas (Fig. 2c-d); espermateca com espículas internas arranjadas em grupos de três a seis, conduto da espermateca e área de união são membranosas. Machos com mesonoto preto, com 1+1 manchas subtriangulares antero-dorsais, pruinosas, com luz lateral, aparece mais nitidamente uma faixa larga, circundando as margens laterais e posteriores; genitália com o basímero maior que o distímero, que possui um esporão apical largo e chato na parte apical da margem apical; e com conspícua carena 


\section{ACTA AMAZONICA}

A

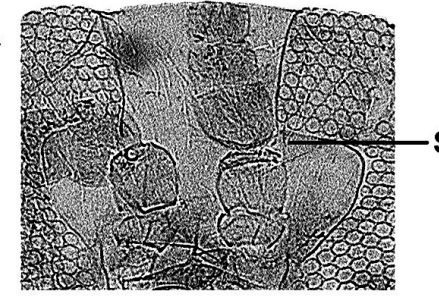

$\mathbf{F}$

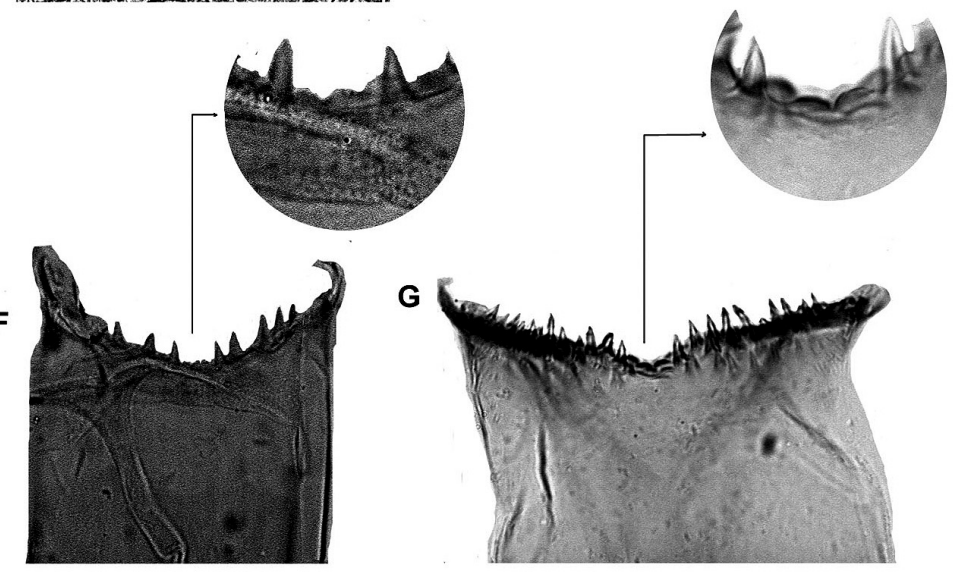

C

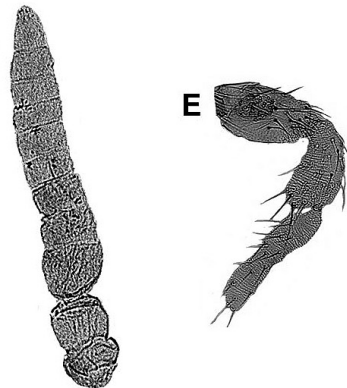

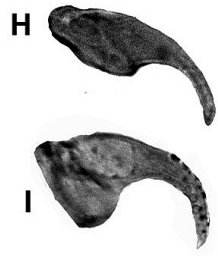

Figura 1 - fêmeas de Shelleyellum gen. nov. a-b- Fronte de Shelleyellum damascenoi e Shelleyellum siolli respectivamente. SIFsutura infra-frontal. c- Antena de Shelleyellum damascenoi; d-e Palpo maxilar de Shelleyellum damascenoi e Shelleyellum siolii respectivamente. f-g- cibário de Shelleyellum damascenoi e Shelleyellum siolii, área em destaque aumentada para mostrar os dentículos rombos. h-i- garras tarsais de Shelleyellum damascenoi e Shelleyellum siolii, respectivamente.

longitudinal (Fig. 2g). Endoparâmeros com espinhos bem desenvolvidos.

IMATUROS: Pupas - Casulo chineliforme, sem projeção anterior; trama do casulo fracamente visível a conspícua; Fronto-clípeo com $2+2$ tricomas frontais simples/bífidas, curtos/longos, fronto-clípeo sem ou com tubérculos arredondados ou arredondados entremeados com agudos. Comprimento da brânquia pode ser menor/igual ou subigual em relação ao corpo/casulo da pupa; brânquia com quatro a seis filamentos branquiais, com os ramos secundários se bifurcando logo na base ou mais distalmente, região anterior e central do tórax sem tubérculos, parte posterior com tubérculos arredondados ou subtriangulares; $5+5$ tricomas centrotoráxicos simples/quadrífidos, $1+1$ tricomas supra-laterais simples, média, filiformes, ápice simples; $3+3$ tricomas laterais simples, filiformes, ápice simples. Larvas - Coloração geral variando de cinza claro a cinza escuro, com faixas escuras nos segmentos, sendo que o primeiro segmento abdominal apresenta sempre a faixa com tonalidade mais escura (material em álcool). Comprimento $=3,7-4,6 \mathrm{~mm}$. Cápsula cefálica, regiões
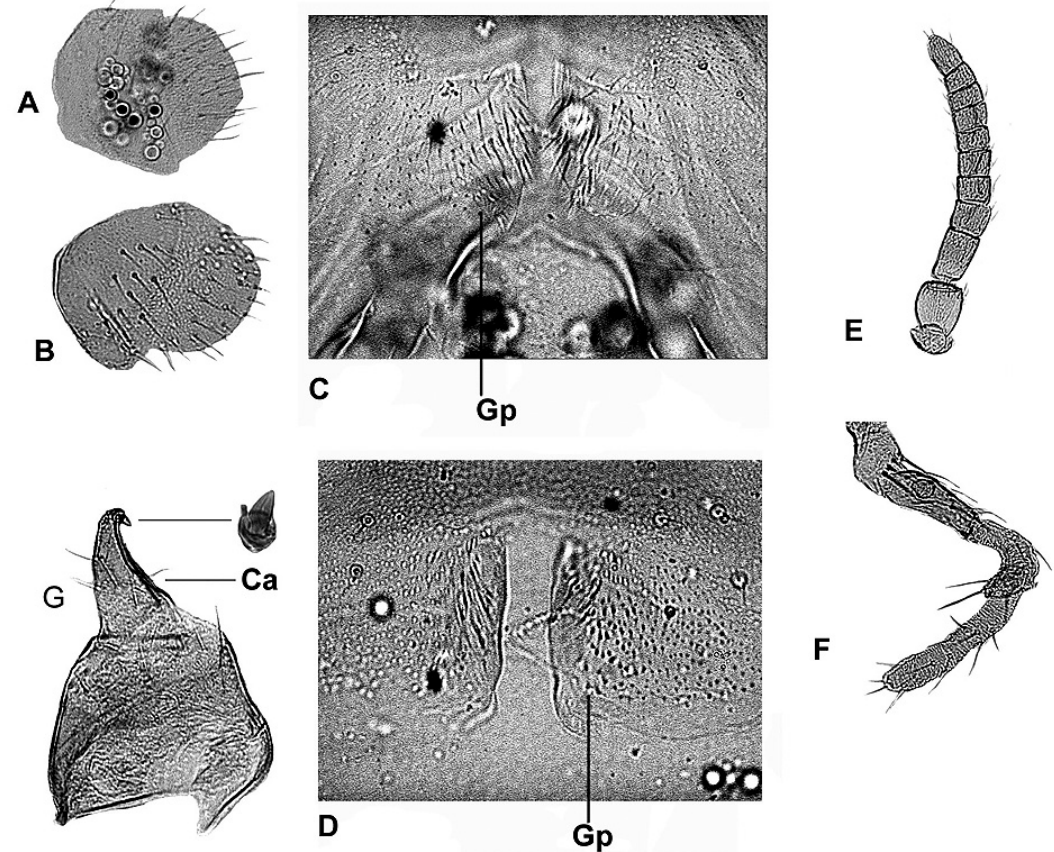

Figura 2. a-b-Cerco e paraprocto de Shelleyellum damascenoi e Shelleyellum siolii, respectivamente. c-d- VIII esternito de Shelleyellum damascenoi e Shelleyellum siolii, Gp-gonapófise; e-g- macho de Shelleyellum siolli. e- antena; f- palpo maxilar; g- basímero e distímero, ampliação destacando o esporão apical do distímero; Cacarena lateral do distímero. 
torácicas e abdominais com setas simples ou bífidas. Contorno do corpo apresentando protuberâncias subtriangulares a arredondadas dorsais que aumentam de tamanho no sentido antero-posterior, nos segmentos abdominais que podem variar de II até VIII (Fig. 8e). Tubérculos ventrais posteriores ausentes ou presentes. Apódema cefálico com setas desde muito pequenas, simples e esparsas até setas grandes simples e/ ou bífidas. Manchas na cabeça positivas. Antenas ultrapassando os ápices das hastes dos leques cefálicos. Segmentos antenais variando desde iguais / subiguais, segmento II maior que o I ou III, segmento antenal III maior que o I ou II. Leques cefálicos normais, com 30-44 raios, fibrilas tipo "weak complex" de Palmer \& Craig (2000) (Fig. 5a-d); cada raio do leque primário apresenta uma mancha escura no ápice do quarto basilar e quando os raios se apresentam juntos o leque cefálico aparenta ter uma linha escura contínua (Fig. 6a-c), dentes hipostomais sendo $1+1$ dentes pontas, um dente central, 3+3 dentes intermediários de tamanho iguais / subiguais entre si, com ligeira tendência de decréscimo de tamanho do mais externo para o mais interno, $2+2$ dentes laterais; fenda gular profunda e variando de sub-hemi-circular até submitral; mandíbula com um ou dois processos láteromandibulares (PLMs), simples, sinuoso (s), e ultrapassando a margem inferior da mandíbula; um dente apical, dois dentes externos, três dentes pré-apicais, o terceiro dente menor que o segundo (podem ser sub-iguais) e ambos menores que $o$ primeiro; 9-13 dentes internos; segundo dente marginal presente, menor que o primeiro, podendo ser curvo, emergindo aparentemente de um projeção lamelar da base do primeiro dente marginal; sem setas supramarginais na mandíbula.

Etimologia: O nome Shelleyellum é em homenagem ao simulidólogo, Dr. Anthony John Shelley, pesquisador aposentado do British Museum of Natural History.

Discussão: Fêmea - Shelleyellum se aproxima de Psaroniocompsa por apresentar a depressão central do cibário com dentes rombos e sem 1+1 elevações laterais, diferente de Cerqueirellum em que a depressão central não possui dentes rombos e também não possui $1+1$ elevações laterais, e diferente de Coscaroniellum em que a depressão central possui dentes rombos e ocorrem $1+1$ elevações laterais; enquanto Psaroniocompsa apresenta dentículos infra-distais no cibário, em Shelleyellum, Cerqueirellum e Coscaroniellum eles estão ausentes; enquanto Shelleyellum e Cerqueirellum não possuem dentículos sub-basilares nas garras tarsais, Psaroniocompsa e Coscaroniellum possuem. Macho - A proporção do comprimento / largura do pedicelo antenal em Coscaroniellum é igual ou maior que 2, enquanto que em Shelleyellum, Psaroniocompsa e Cerqueirellum é menor ou igual a 1,5; distímero em Shelleyellum cônico, em Psaroniocompsa subquadrático, em Cerqueirellum subtriangular e em Coscaroniellum podomórfico; enquanto o distímero em Shelleyellum apresenta uma carena longitudinal, em Psaroniocompsa, Cerqueirellum e Coscaroniellum tal carena não ocorre; enquanto em Psaroniocompsa a localização do esporão do distímero é na posição sub-mediana, em Shelleyellum, Cerqueirellum e Coscaroniellum é na margem apical. Pupa - Comprimento das brânquias variam de 1,14 até $2,43 \mathrm{~mm}$, medidas do casulo do lado ventral - dorsal: 2-3,4 e 1,7 - 2,5 mm, respectivamente; tubérculos do tórax uniformemente distribuídos em Psaroniocompsa, Coscaroniellum e Cerqueirellum, com exceção de $C$. venezuelense, que possui tubérculos triangulares pequenos e em número muito reduzido, descrito originalmente com tubérculos ausentes (Ramírez-Pérez \& Peterson, 1981) (material examinado: material tipo em lâmina, 1 macho e respectiva exúvia pupal e 1 fêmea com respectiva exúvia pupa, Villa de Cura, Aragua, Venezuela), sendo que em Shelleyellum não são uniformemente distribuídos, concentrando-se na parte antero-posterior do tórax, com ausência ou escassez de tubérculos na parte antero-central. Larva - Setas supra-marginais da mandíbula presentes em Cerqueirellum e ausentes em Psaroniocompsa, Shelleyellum e Coscaroniellum; tubérculos nos tergitos abdominais presentes em Shelleyellum e ausentes em Coscaroniellum, Cerqueirellum e Psaroniocompsa; Cerqueirellum com fibrilas dos leques cefálicos do tipo "standard" (Palmer \& Craig 2000), enquanto que Psarioniocompsa, Coscaroniellum e Shelleyellum apresentam do tipo "weak complex" (Palmer \& Craig 2000); Dentes hipostomiais intermediários: mediano não ultrapassando a metade do comprimento do dente externo intermediário = Coscaroniellum, dente hipostomial mediano intermediário com tamanho igual ou subigual ao dente externo intermediário = Shelleyellum, Psaroniocompsa e Cerqueirellum.

Aspectos taxonômicos: As espécies de Shelleyellum apresentam convergência de caracteres larvais do abdome coberto de setas e tubérculos dorsais, com os gêneros não neotropicais Edwardsellum, Etiópico e Byssodon, Etiópico e Holoártico. No entanto, os demais caracteres dos imagos os diferenciam nitidamente (Py-Daniel, 1988).

\section{Shelleyellum damascenoi comb. nov.}

\section{Simulium (Psaroniocompsa) damascenoi Py-Daniel, 1988}

Fêmea: Comprimento do corpo: $1,83 \mathrm{~mm}$, comprimento da asa: 1,65 mm. Cabeça: Comprimento da antena 360-370 $\mu \mathrm{m}$ (Fig. 1c), menor que a do macho, com pedicelo, escapo e $2 / 3$ basilares do $1^{\circ}$ flagelômero amarelo claro, flagelômeros seguintes escuros. Palpo maxilar marrom, vesícula sensorial do palpo de formato alongado, com aproximadamente $1 / 2 \mathrm{da}$ comprimento do palpo que a sustenta. Comprimento do palpômero III = ao palpômero IV: $75,48 \mu \mathrm{m}$, palpômero V:129,62 $\mu \mathrm{m}$. Proporção palpal dos palpômeros III - V: $(\mathrm{N})=1: 1: 1,72$ (Fig. 1d). Mandíbula com 22-25 dentes na borda interna e 5 dentes na borda externa; maxila com 19-20 dentes (8 dentes na margem interna, 1 dente central e 10-11 dentes na margem externa). Tórax: (descrição de coloração retirada de Hamada et al. 2003): Mesonoto enegrecido, com luz incidindo frontalmente aparecem 1+1 manchas dorsais pruinosas, que se estendem desde a região anterior até a posterior (reduzindo a largura no sentido antero-posterior); com luz lateral, aparece mais nitidamente, uma faixa larga pruinosa que circunda lateral e 


\section{ACTA AMAZONICA}

posteriormente o mesonoto. Mesonoto com um par de listras prata finas. Abdome: Tergitos distais abdominais (VI-IX) com aparência brilhosa, tergitos III-V marrom, com uma placa média com aparência brilhosa, tergitos 1-2 marrom com pruinosidade prata.

Macho (descrição baseada no texto e figuras de Hamada $e t$ al., 2003): Comprimento do corpo 1,65 mm; comprimento das asas $1,42 \mathrm{~mm}$. Comprimento da antena $=400 \mu \mathrm{m}$, de cor marrom escura, exceto o escapo, pedicelo e metade distal do $1^{\circ}$ flagelômero, amarelo, razão da proporção comprimento / largura do segmento antenal II do macho não ultrapassa 1,5. Palpo marrom, vesícula sensorial pequena, sub-esférica, proporção palpômeros III-V = 1:1,29:2. Tórax: Mesonoto preto, com duas manchas quadrangulares antero-laterais, irregulares na região posterior. Anepisterno e catepisterno marrons com
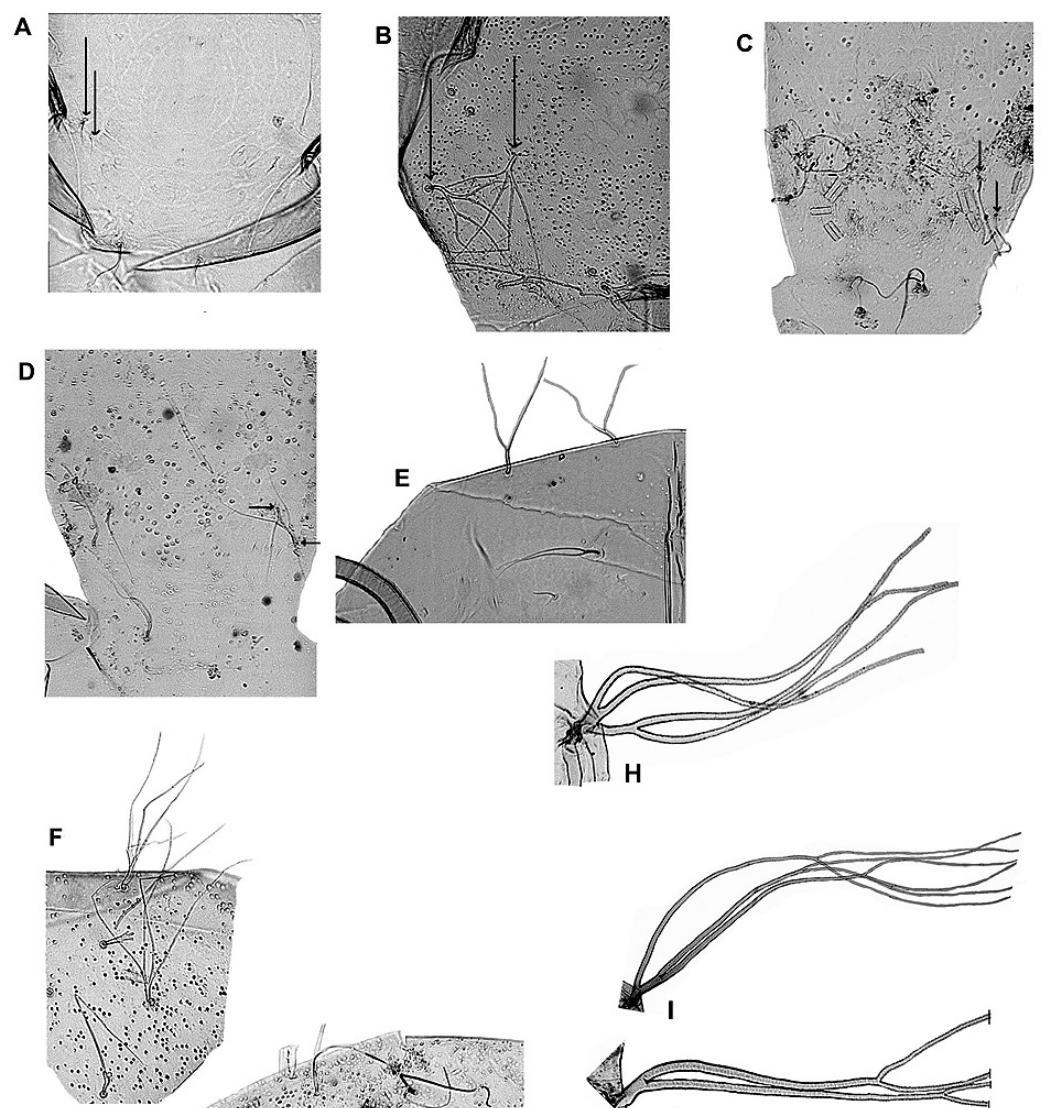

G

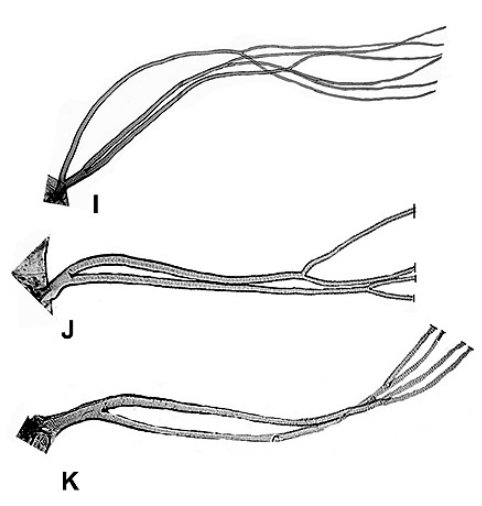

Figura 3 - a-d- Fronto-clípeo de pupas de Shelleyellum gen. nov. a- Shelleyellum damascenoi, b-Shelleyellum guaporense, c-Shelleyellum lourencoi, d-Shelleyellum siolii. Setas apontam para tricomas frontais. e-f- Parte do tórax de pupa de Shelleyellum damascenoi e Shelleyellum guaporense com tricomas. g- Shelleyellum siolii. h-k- Filamentos branquiais de Shelleyellum Nov. Gen. h- Sbelleyellum damascenoi; i-Shelleyellum guaporense; j- Shelleyellum lourencoi; $\mathrm{k}$ - Shelleyellum pruinosidade prata, escutelo marrom escuro com pelos marrom-dourados, posnoto marrom com pubescência prata. Abdome: Escleritos abdominais marrom, áreas membranosas marrom, pelo basal marrom. Tergitos marrom escuros. Placa entral mais larga que alta, esclerito mediano oval, sem incisão

Pupa: Comprimento da pupa: 1,8-2,0 mm. Casulo chineliforme, sem projeção anterior; trama do casulo fracamente visível. Margem anterior reforçada e mais escurecida. Comprimento dorsal do casulo: $1,9-2,1 \mathrm{~mm}$, ventral $=2,0-2,2$

Fronto-clípeo sem tubérculos (Fig. 3a), com 2+2 tricomas frontais simples, curtos (comprimento do tricoma não ultrapassa 1/3 da largura da largura do fronto-clípeo da pupa), e $1+1$ tricomas faciais simples ou bífidos. Comprimento da brânquia $=1,14-1,57$ $\mathrm{mm}$ (menor que o comprimento da pupa). Brânquia com quatro filamentos branquiais terminais, dois ramos primários bifurcando-se logo na base, bifurcação do ramo ventral um pouco mais longo que o ramo dorsal. Fórmula branquial: 1[1(2)+1(2)] (Fig. 3h). Parte anterior do tórax sem tubérculos, parte posterior com tubérculos arredondados ou subtriangulares; $5+5$ tricomas centrotoráxicos simples / quadrífidos (Fig. 3e). Abdome: Tergitos de I-V sem dentículos anteriores. Tergitos VI-IX com 1+1 áreas anteriores apresentando dentículos. Tergito I com $1+1$ setas filiformes, fronto-laterais. Tergito II com $5+5$ setas filiformes; sendo que $4+4$ com o ápice no sentido longitudinal do abdome $\mathrm{e}$ $1+1$ setas transversais, frontais ao espaço entre as duas setas mais externas ou fronto-laterais a seta mais externa. Tergitos III-IV com $4+4$ ganchos simples na região posterior e $1+1$ setas filiformes, transversais, frontais ao espaço entre ganchos mais externos). Tergito V com $5+5$ setas filiformes, simples, no terço posterior. Tergitos VI-VII com 3+3 setas espiniformes, simples ou bífidas, no terço posterior; tergito VIII com $2+2$ setas simples/bífidas, espiniformes; tergito IX com $1+1$ setas espiniformes, simples. Esternitos III-VIII com 1+1 áreas com dentículos em forma de pente. Esternito III sem setas, podendo às vezes aparecer 1+1 microsetas; esternito IV com $2+2$ setas, simples, externas ao 1+1 ganchos bífidos e/ou trífidos, com área membranosa longitudinal entre os ganchos e as setas. Segmento V com 2+2 ganchos bífidos, muito próximos entre 


\section{ACTA AMAZONICA}

SIMULIIDAE (DIPTERA:CULICOMORPHA) NO BRASIL $\mathrm{XI}$ - Shelleyellum GÊNERO NOVO

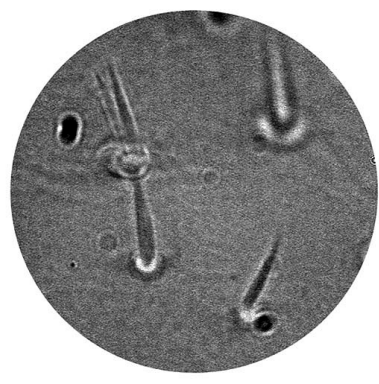

A

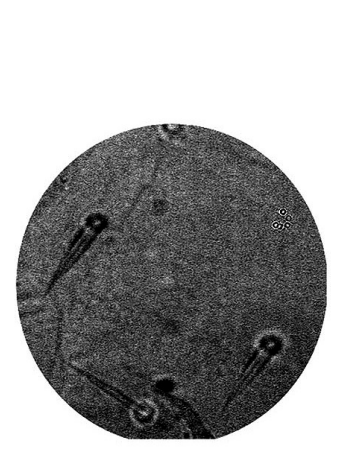

B

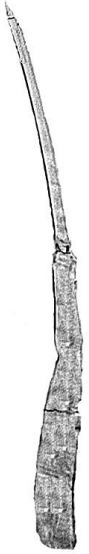

C

D

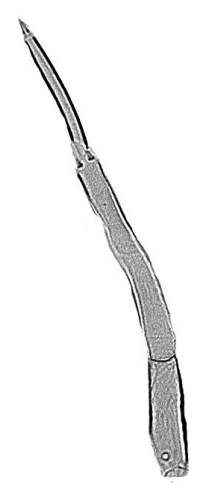

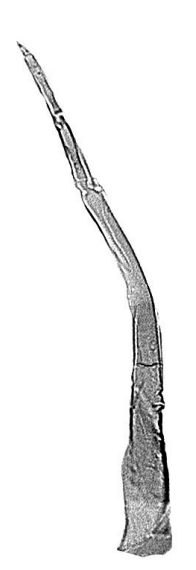

E

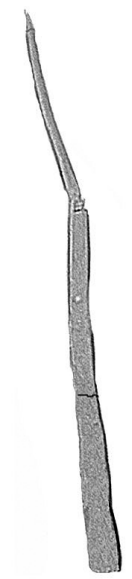

$\mathbf{F}$
Figura 4 - a-b- setas do apódema cefálico larval; a- Shelleyellum lourencoi; b- Shelleyellum siolii; c-f- antenas de larvas; cShelleyellum damascenoi; d- Sbelleyellum guaporense; eShelleyellum lourencoi; f-Shelleyellum siolii.

si e $2+2$ setas espini-filiformes, latero-externas aos ganchos externos. Segmentos externais VI-VII com $2+2$ ganchos, os externos simples ou bífidos, os internos bífidos. Nas membranas intersegmentares tanto nos tergitos como nos externitos existem 1+1 microsetas, espiniformes, translúcidas.

Larva: Comprimento $=3,7-3,9 \mathrm{~mm}$. Máxima largura da cápsula cefálica $=0,4-0,45 \mathrm{~mm}$. Cápsula cefálica, regiões torácicas e abdominais com setas simples ou bífidas. Contorno do corpo apresentando protuberâncias subtriangulares dorsais que aumentam de tamanho no sentido antero-posterior, nos segmentos abdominais de II-V (2+2 nos segmentos II-V e 1+1 no segmento VI) e uma protuberância central, arredondada no segmento VIII. Tubérculos ventrais posteriores ausentes. Apódema cefálico castanho claro com setas muito pequenas, simples e esparsas. Antenas ultrapassando os ápices das hastes dos leques cefálicos. Terceiro segmento antenal mais escuro que os anteriores. Proporção entre os segmentos antenais I/II/ III = 1:1,50-1,72:0,90-1,02 (segmento II com pelo menos 1/3 ou mais longo que o segmento III) (Fig. 4c). Leques cefálicos normais, com 38-44 raios, com comprimento do raio $=700,6$ ìm (medidas tomadas nos raios do centro do leque). Escleritos cervicais pequenos, elipsóides e livres na membrana. Hipostômio com 3-4+3-4 setas laterais e 2-3+2-3 setas pequenas no disco; $2+2$ dentes laterais e 4-6+4-6 serrilhas (Fig. 7e). Proporção entre hipostômio / ponte gular $/$ fenda gular $=1$ : 0,45-0,5:1,7-2,0. (Fig. 7a). Mandíbula com um PLM, simples, sinuoso, e ultrapassando a margem inferior da mandíbula (Fig. 8a). Ápice do esclerito lateral com cinco pentes e com cinco a sete setas por pente. Esclerito anal com os braços anteriores mais curtos que os posteriores, associados com setas de pontas simples a múltiplas, bem esclerotizadas. Disco anal com 70-76 fileiras de ganchos, com 14-17 ganchos por fileira. Lóbulos anais com 4-6 lóbulos digitiformes em cada um dos três lobos primários.

Tipos: Holótipos e parátipos depositados na Coleção de Invertebrados do INPA (Simuliidae), Manaus, Amazonas.

Localidade Tipo: Igarapé do Henrique, rodovia BR-156, Km 272, Amapá, Brasil.

Material examinado: oito larvas e duas pupas em álcool, INPA-6185, 23.ii.1987, Igarapé Davi Grande, rodovia BR-156, Km 290, V. Py-Daniel, leg.; Igarapé do Henrique, rodovia BR156, Km 272, Amapá, Brasil, uma fêmea em lâmina com respectiva exúvia pupal, lâmina $\mathrm{N}^{\circ}$ 6186-1, holótipo, uma fêmea em lâmina com respectiva exúvia pupal, lâmina $\mathrm{N}^{\circ}$ 6186-2, parátipo, cinco larvas em lâminas (6186-3 a 7), parátipos, 24 larvas (no álcool: INPA-6186, 23.ii.1987, V. Py-Daniel leg); quatorze larvas, quatro pupas e uma exúvia pupal (todos no ácool), INPA-6290, 10.vi.1986, primeira cachoeira grande do Igarapé do Uruá, afluente do rio Mapuera, Pará, Brasil, col. Py-Daniel,V. \& Barbosa,U.C.

Bionomia: Habitat: No estado do Amapá, S. damascenoi foi encontrada em correntes com 8-100m de largura, com condutividade elétrica menor a $10 \mathrm{mS} / \mathrm{cm}$, temperatura entre $24 \mathrm{e} 28^{\circ} \mathrm{C}, \mathrm{pH} 4,7-6,9$, em rios de leito rochoso, em áreas de floresta e de savana, utilizando como substratos folhas decíduas, folhas de vegetação que cresce na beira do córrego e de plantas Podostemaceae, e rochas (Hamada et al., 2003). Existem poucas informações sobre a bionomia desta espécie.

Distribuição: espécie registrada apenas para o Amapá, em vários igarapés ao longo da estrada Macapá-Oiapoque (Py-Daniel, 1988; Hamada et al., 2003): igarapé perto de Caciporé, BR-156, aproximadamente a 90Km de Oiapoque, $03^{\circ} 11^{\prime} \mathrm{N} 51^{\circ} 32^{\prime} \mathrm{W}$; igarapé Água Branca, perto a Vila Carnot, BR-156 MacapáOiapoque, $02^{\circ} 40^{\prime} \mathrm{N} 51^{\circ} 21^{\prime} \mathrm{W}$; Rio Cachoeira Grande, cidade Amapá, BR-156 Macapá-Oiapoque, 0209’N 5055’W; igarapé Davi Grande, cidade Amapá, BR-156 Macapá-Oiapoque, Km 290, 015' $\mathrm{N} 50^{\circ} 51^{\prime} \mathrm{W}$; igarapé do Henrique, cidade Amapá, BR-156, Macapá-Oiapoque, $\mathrm{Km} 272,01^{\circ} 45^{\prime} \mathrm{N} 50^{\circ} 52^{\prime} \mathrm{W}$. A distribuição da espécie é mostrada na Figura 9a.

Histórico: Espécie descrita por Py-Daniel (1988) a partir de larva, pupa e adulto fêmea. Hamada et al. (2003) fizeram a descrição do macho e adicionaram alguns caracteres taxonômicos para a fêmea, tais como coloração do tórax e abdome. 


\section{ACTA AMAZONICA}

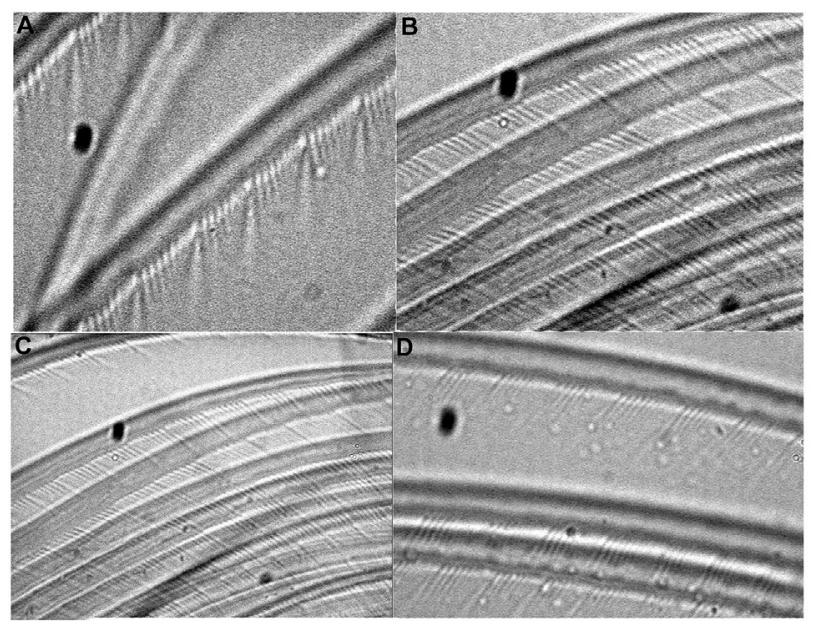

Figura 5 - fibrilas dos raios do leque cefálico de Shelleyellum Nov. Gen. a- Shelleyellum damascenoi; b- Shelleyellum guaporense; c- Shelleyellum lourencoi; d- Shelleyellum siolii.

\section{Shelleyellum guaporense comb. nov.}

Simulium (Psaroniocompsa) guaporense Py-Daniel, 1989

Imagos: Não conhecidos.

Pupa: Comprimento do casulo, dorsal $=2,5 \mathrm{~mm} /$ ventral $=$ 3,3-3,4 mm. Comprimento dos filamentos branquiais $=2,2-2,3$ $\mathrm{mm}$. Casulo chineliforme, com trama visível, cobrindo apenas o terço posterior do tórax com a borda anterior reforçada e mais escurecida, com $1+1$ reduzidos projeções anterodorsais. Brânquias de cor castanha clara, sendo que da base comum partem dois troncos primários: o dorsal curto $(0,14 \mathrm{~mm})$ que se subdivide dando dois secundários, que por sua parte se subdividem dando um total de quatro filamentos terminais; 0 ventral longo $(1,2-1,6 \mathrm{~mm})$ que se bifurca dando dois filamentos terminais, totalizando seis filamentos terminais. Fórmula branquial: 1[1(1(2)+1(2)+1(2)] (Fig. 3i). As brânquias possuem o retículo composto de tubérculos enfileirados. Ápice dos filamentos afilado. Fronto-clípeo com tubérculos arredondados e alguns agudos. Ornamentação do fronto-clípeo com 2+2 tricomas frontais, longas, trífidas e/ou com múltiplas (3-4 ramos) e longos (comprimento do tricoma igual ou ultrapassa a metade da largura do fronto-clípeo da pupa) (Fig. 3b); $1+1$ tricomas faciais com a mesma ramificação que os tricomas frontais. Estojos antenais lisos. Tórax: com a metade anterior apresentando tubérculos de tamanho pequeno sendo desde agudos a arredondados e com a metade posterior apresentando tubérculos arredondados simples com predominância de tubérculos arredondados; quetotaxia do tórax sendo 5+5 tricomas centro-dorsais bífidas, trífidas e/ou quadrífidas (Fig. 3f), médias, filiformes e com o ápice simples. Abdome: Tergitos abdominais nitidamente membranosos. Tergitos I-V sem dentículos anteriores. Tergitos VI-IX com 1+1 áreas anteriores apresentando dentículos tanto do tipo pequeno como do grande. Tergito I com $1+1$ longas setas filiformes fronto-laterais, não apresentando setas na região centro-anterior. Tergitos II a
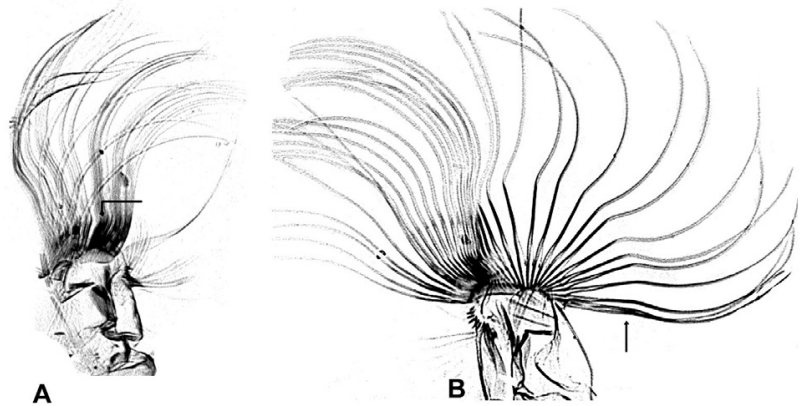

A

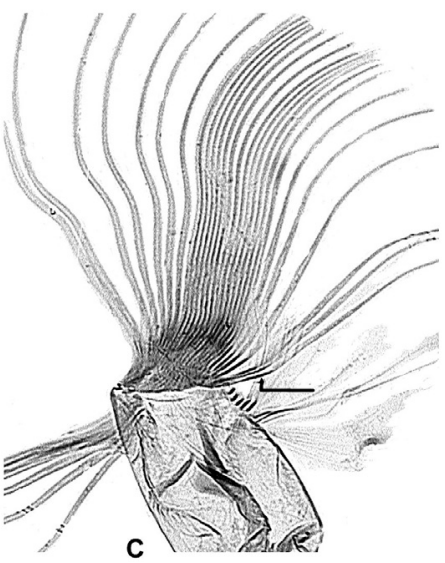

Figura 6 - Leque cefálico de larva de Shelleyellum gen. nov. aShelleyellum damascenoi, b: Shelleyellum lourencoi, c: Shelleyellum siolii.

IV como em $S$. damascenoi. Tergito V com 3-4+3-4 setas espiniformes, simples ou bífidas, no terço posterior. Tergitos VI-VII com $2+2$ setas espiniformes, simples, no terço posterior. Tergito VIII com $3+3$ setas espiniformes, simples. Tergito IX sem setas. Ao longo do abdome, ao nível pleural, existem $3+3$ setas espiniformes por segmento. Espinhos terminais do abdome pequenos. Esternitos III-IV e VI-VIII apresentando áreas com dentículo em forma de pente. Esternito $\mathrm{V}$ não apresenta tais áreas. Esternito III sem setas; esternito IV com $3+3$ setas simples, espiniformes. Esternitos VI-VIII divididos medianamente, por áreas membranosas estriadas, longitudinais. Placas esternais do esternito $\mathrm{V}$ com $2+2$ ganchos bífidos-trífidos, muito próximos e com $2+2$ setas espinifiliformes, latero-externas aos ganchos externos. Esternitos VI-VII com $2+2$ ganchos, sendo os externos simples, os internos bífidos e/ou tríidos, e com $3+3$ setas espini-filiformes, $1+1$ setas frontais aos ganchos externos, $1+1$ setas entre os ganchos externos e internos, $1+1$ setas no segmento VI láteroexternas aos ganchos externos, no esternito VII frontais as setas inter-ganchos. Nas membranas intersegmentares, nos tergitos e nos esternitos existem 1+1 microsetas, espiniformes, translúcidas. Sem áreas esclerotizadas, nas estrias das membranas intersegmentares.

Larva: Comprimento do corpo 4,37 mm. Regiões toráxica e abdominal com setas simples; os últimos segmentos abdominais dorsalmente com uma fileira transversal de escamas 

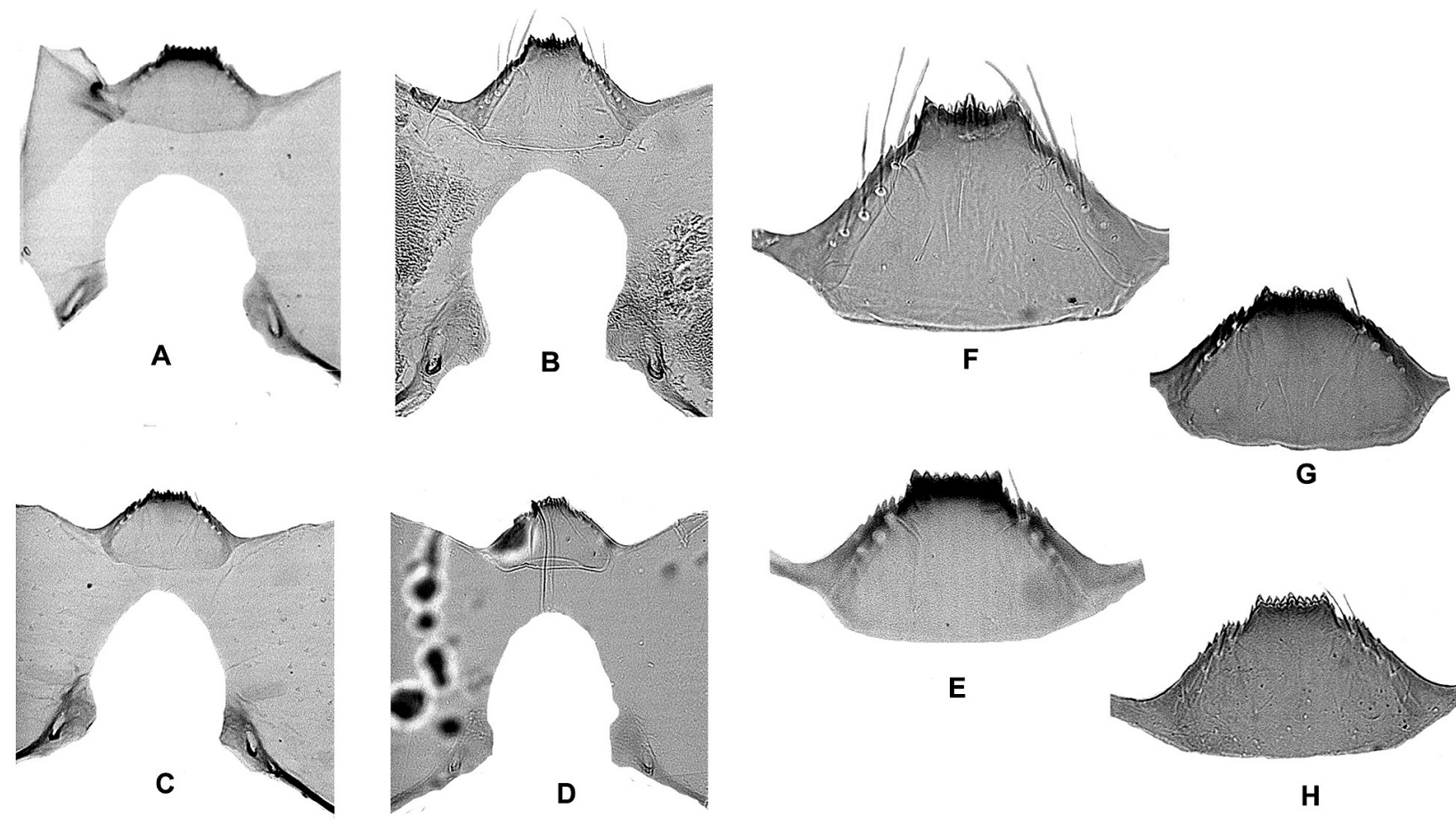

G

E

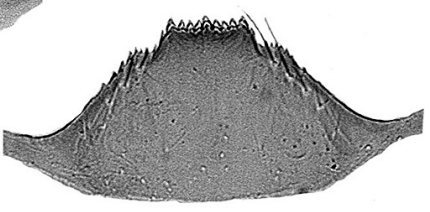

H

Figura 7 - a-d- Fenda gular, ponte e hipostômio de a- Shelleyellum damascenoi; b- Shelleyellum guaporense; c- Shelleyellum lourencoi; d-Shelleyellum siolii; e-h- Hipostômio. e-Shelleyellum damascenoi; f- Shelleyellum guaporense; g-Shelleyellum lourencoi; h- Sbelleyellum siolii.

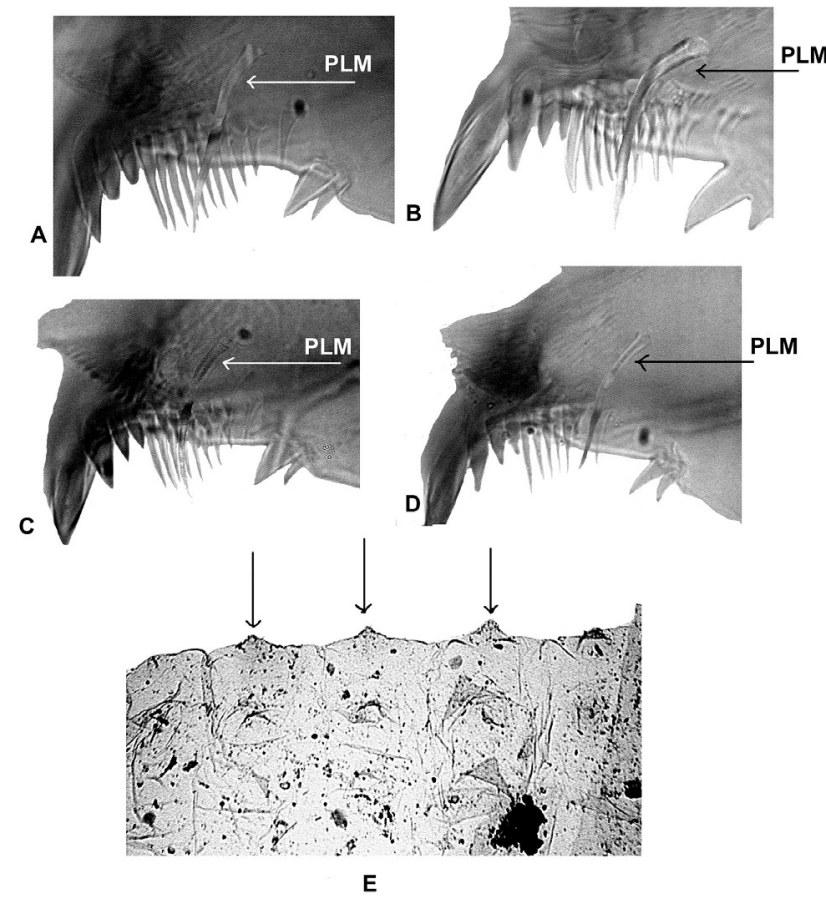

Figura 8 - a-d- mandíbulas de larvas de Shelleyellum nov. gen. aShelleyellum damascenoi; b- Shelleyellum guaporense; cShelleyellum lourencoi; d- Shelleyellum siolii; PLM- processo látero-mandibular com coloração alterada; e- parte dorsal do abdome de larva de Shelleyellum lourencoi. achatadas, poliapicais. Contorno do corpo apresenta protuberâncias subtriangulares dorsais que aumentam de tamanho no sentido anteroposterior, nos seis primeiros segmentos abdominais, com $1+1$ nos segmentos I e VI; $2+2$ nos segmentos II-V, e ausentes no segmento VII; a região posterior dos tubérculos é mais escurecida e apresenta escamas evidentemente esclerotizadas; ventralmente apresenta protuberâncias arredondadas que também aumentam de tamanho no sentido antero-posterior, mas sem diferenciação tegumentar. Tubérculos ventrais posteriores subtriangulares; tubérculos laterais posteriores arredondados. Apódema cefálico castanho claro com setas simples, afiladas, relativamente longas e em grande número. Proporções dos segmentos antenais I:II:III = 1:0,92:1,42-1,5 (Fig. 4d); segmento antenal III mais escuro que os anteriores. Leques cefálicos com 37-39 raios. Escleritos cervicais pequenos, elipsóides e livres na membrana. Hipostômio com 5+5 setas laterais e 3+3 no disco; dentes hipostomiais: sendo $1+1$ dentes pontas, um dente central, $3+3$ dentes intermediários, $1+1$ dentes externos e $1+1$ internos iguais e maiores que o mediano, $2+2$ dentes laterais e 7+7 serrilhas; os dentes central, pontas e intermediários apresentam uma projeção basilar (Fig. 7f). Fenda gular (Fig. 7b) profunda e submitral; proporção entre o hipostômio, ponte gular e fenda gular: 1: 0,15:1,75; mandíbula com dentes externos; um dente apical; quatro dentes pré-apicais que decrescem no sentido antero-posterior; 13 dentes internos; dois dentes marginais sendo o segundo alargado e têm a base, anteriormente, ligada ao primeiro; com um PLM simples, fino, 


\section{ACTA AMAZONICA}

SIMULIIDAE (DIPTERA:CULICOMORPHA) NO BRASIL $\mathrm{XI}$ - Shelleyellum GÊNERO NOVO
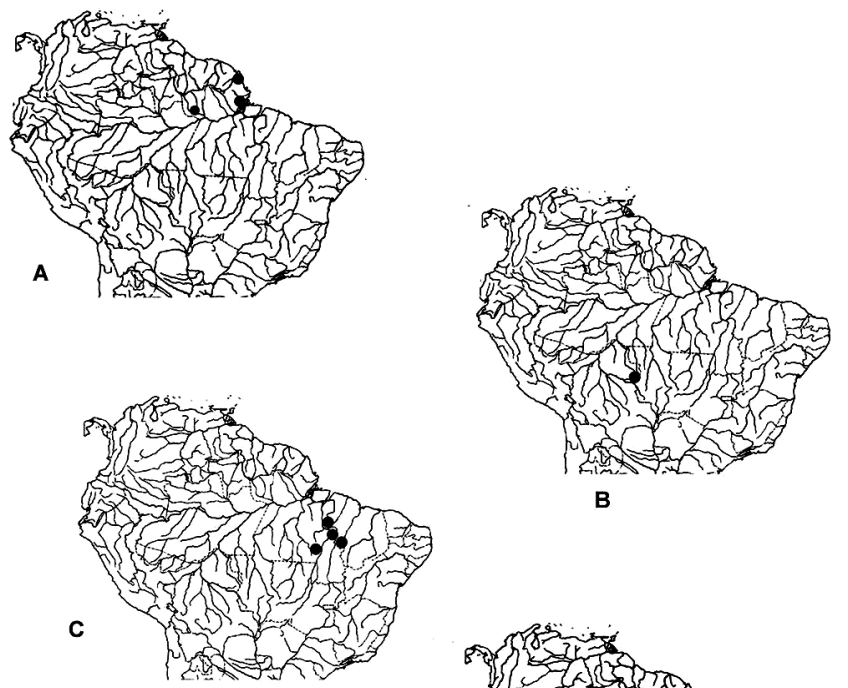

B

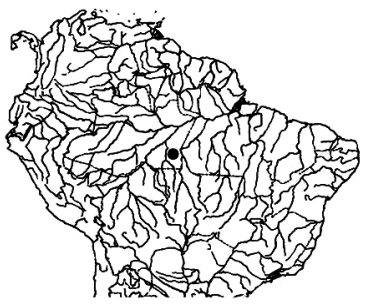

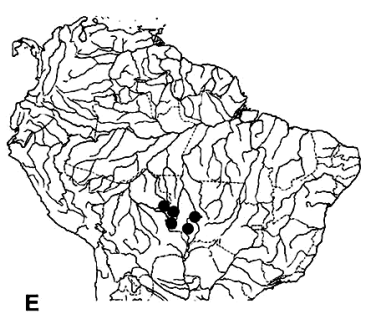

Figura 9 - a-e- Mapa de distribuiçao das espécies de Shelleyellum nov. gen. a- Shelleyellum damascenoi; b- Shelleyellum guaporense; c- Shelleyellum lourencoi; d- Shelleyellum tergospinosum; e- Shelleyellum siolii.

sinuoso e com o ápice ultrapassando a margem inferior da mandíbula (Fig. 8b). Região anterior a cavidade anal com poucos espinhos simples ou bífidos, com esclerotização fraca. Disco anal com 79 fileiras de ganchos e com 10-15 ganchos por fileira.

Material tipo, material examinado e distribuição: Brasil, Rondônia: Rodovia RO-399, Bacia do rio Guaporé, Igarapés da Cachoeira e Igarapé Ponte de Pedra, sendo este último no km 27, Fazenda Régis (Vilhena, Colorado), uma pupa em lâmina (INPA 5849-1-Holótipo), material adicional da localidade tipo em lâmina: 2 larvas e 1 pupa (parátipos, série 5849 de 2-4). Além do holótipo e parátipos, foram examinadas 1 larva (em álcool)-INPA 5851, 14.vi.1981. V. Py-Daniel, col., no Igarapé da Cachoeira, rodovia RO - 399 (Vilhena / Colorado). O material tipo está depositado na Coleção de Invertebrados do INPA (Simuliidae), Manaus, Amazonas. A distribuição da espécie é mostrada na figura $9 \mathrm{~b}$.

Bionomia: Não há informações publicadas. Os espécimes foram coletados em igarapés pequenos e/ou médios, de área aberta, antropizadas na beira de estrada, foram coletados somente imaturos em folhas caídas.

Histórico: Nas descrições de Py-Daniel (1988), feitas para $S$. siolii, S. lourencoi e $S$. damascenoi o primeiro segmento abdominal das larvas apresentava protuberâncias

subtriangulares (na realidade a numeração dos segmentos foi refeita por Py-Daniel,1989: S. siolii, S. lourencoi e S. damascenoi sem tais protuberâncias, S. guaporense com $1+1$ protuberâncias.

\section{Shelleyellum lourencoi comb. nov.}

\section{Simulium (Psaroniocompsa) lourencoi Py-Daniel, 1988}

Adultos: Existe uma breve descrição do macho e da fêmea em Hamada \& Azevedo (2002), sem informações adicionais quanto a diagnose.

Pupa: Comprimento do casulo, dorsal $=1,7 \mathrm{~mm}-1,9 \mathrm{~mm} /$ ventral $=2,03-2,18 \mathrm{~mm}$. Comprimento dos filamentos branquiais $=1,92-2,43 \mathrm{~mm}$. Casulo chineliforme, com trama visível, conspícua, com borda anterior reforçada e mais escurecida, com uma pequena projeção antero-dorsal. Frontoclípeo com $2+2$ tricomas frontais simples/bífidos, longos (comprimento do tricoma ultrapassa $1 / 3$ da largura do frontoclípeo da pupa) (Fig. 3c), e 1+1 tricomas faciais simples/bífidos, longos. Fronto-clípeo com tubérculos arredondados. Tórax: Brânquia com quatro filamentos branquiais, mais longas que o corpo da pupa, sendo que da base partem dois ramos primários longos, o ventral que se bifurca à aproximadamente na metade do comprimento total da brânquias e o dorsal se bifurca a aproximadamente a $1 / 3$ do comprimento total da brânquia; fórmula branquial: 1[1(2)+1(2)] (Fig. 3j). Tórax com tubérculos predominantemente arredondados, embora possua na parte posterior alguns tubérculos subtriangulares; $5+5$ tricomas centro-toráxicos simples/bífidos. Abdome: Como em $S$. damascenoi.

Larva: Comprimento $=3,2-3,7 \mathrm{~mm}$. Máxima largura da cápsula cefálica $=0,36-0,43 \mathrm{~mm}$. Cápsula cefálica, tórax $\mathrm{e}$ abdome com setas simples ou bífidas. Contorno do corpo apresentando protuberâncias subtriangulares dorsais que aumentam de tamanho no sentido antero-posterior, nos segmentos abdominais de II-V ( $2+2$ nos segmentos II-V e 1+1 no segmento VI) e sem apresentar nenhuma no segmento VII ou VIII. Tubérculos ventrais posteriores presentes e subtriangulares. Apódema cefálico castanho claro com setas simples/ou bífidas em grande quantidade (Fig. 4a). Antenas ultrapassando os ápices das hastes dos leques cefálicos. Terceiro segmento antenal mais escuro que os anteriores. Proporção entre os segmentos antenais I/II/III = 1:1-1,17: 0,951,06 (Fig. 4e). Leques cefálicos com 30-33 raios, e comprimento do raio $=689,6$ im (medidas tomadas nos raios do centro do leque). Escleritos cervicais pequenos, elipsóides e livres na membrana. Hipostômio com 3-4+3-4 setas laterais e 2-3+2-3 setas pequenas no disco; dentes hipostomais intermediários de tamanho iguais / subiguais entre si (o dente mediano pode ser ligeiramente menor que os demais) e 4-6+4-6 serrilhas (Fig. 7g). Proporção entre hipostômio / ponte gular / fenda gular: 1:0,39-0,42:1,6-2,0 (Fig. 7C). Mandíbula com um PLM, simples, sinuoso, e ultrapassando a margem inferior da mandíbula; oito a 11 dentes internos; segundo dente marginal presente, menor que o primeiro, podendo ser curvado, emergindo aparentemente de um projeção lamelar da base do 
primeiro dente marginal (Fig. 8c). Tubérculos posteriores (1+1) ventrais abdominais grandes subtriangulares, $\mathrm{e} 1+1$ tubérculos posteriores laterais reduzidos e arredondados. Esclerito anal com os braços anteriores mais curto que os posteriores, associados com setas de pontas múltiplas. Disco anal com 6265 fileiras de ganchos, com 12-13 ganchos por fileira. Lobos anais com 6-8 lóbulos digitiformes em cada.

Tipos, Material examinado e Distribuição: Material tipo depositado na Coleção de Invertebrados do INPA (Simuliidae) do INPA, Manaus, Amazonas. Material examinado: Brasil, Goiás: Rio Bandeira, Bacia do Rio Tocantins, rodovia BR-153, a $102 \mathrm{Km}$ distante da fronteira estadual Goiás / Maranhão, uma exúvia pupal em lâmina (6190-1) - Holótipo, três larvas em lâmina (6190-2, 3 e 4) - Parátipos, uma exúvia pupal em lâmina (61901); Parátipo, 39 larvas e duas pupas (no álcool) - INPA-6190, 04.iii.1987, V. Py-Daniel leg.; Pará: Córrego São José, Bacia do rio Araguaia, afluente do rio Arraia do Araguaia, localidade "Restaurante Mineiro", $50 \mathrm{Km}$ depois da cidade Conceição do Araguaia ( $8^{\circ} 20^{\prime} 08^{\prime \prime}$ ' $\left.49^{\circ} 10^{\prime} 58^{\prime \prime} \mathrm{W}\right)$, estrada entre esta cidade e Redenção, uma larva (no álcool) - INPA-6192, 03.iii.1987, V. PyDaniel leg. Hamada \& Azevedo (2002) assinalaram a espécie em Carolina, Estreito e Riachão, cidades próximas ao rio Tocantins. A distribuição para a espécie é mostrada na Figura 9c.

Bionomia: Não há informações sobre a bionomia dessa espécie além do registro de coleta nos córregos e igarapés.

\section{Shelleyellum siolii comb. nov.}

\section{Simulium (Psaroniocompsa) siolii Py-Daniel, 1988}

Adulto: Veias alares Sc e seção basilar da R sem setas. Antenas do macho e da fêmea de tamanhos subiguais.

Fêmea: Comprimento do corpo: 2,23 mm, comprimento da asa: $1,43 \mathrm{~mm}$. Comprimento da antena 360-380 $\mu \mathrm{m}$ (Fig. 1b), com pedicelo, escapo e $2 / 3$ basilares do $1^{\circ}$ flagelômero amarelo claro, flagelômero seguintes escuros. Palpo maxilar marrom, vesícula sensorial do palpo de formato alongado, com aproximadamente $1 / 2$ da comprimento do palpo que a sustenta. Comprimento do palpômero III: $74,1 \mu \mathrm{m}, 81,5 \mu \mathrm{m}$, palpômero V: 129,62 $\mu \mathrm{m}$ (colapsado). Proporção palpal III:IV:V $=1: 1: 1,75$ (Fig. 1e). Maxila com 21 dentes na borda interna e 7 8 dentes na borda externa; mandíbula com 23-24 dentes na borda externa e oito dentes na margem interna. Tórax: Coloração geral preta. Mesonoto enegrecido, com luz incidindo frontalmente aparecem $1+1$ faixas dorsais pruinosas, que se estendem desde a região anterior até a posterior, reduzindo a largura antero-posterior; com a luz lateral aparece mais nitidamente uma faixa larga pruinosa que circunda lateral e posteriormente o mesonoto. Úmeros também com pruina alvacenta. Mesonoto com escamas amarelo-esverdeadas. Mesepisterno, catepisterno e mesepimero enegrecidos e com pruina alvacenta.

Macho: Comprimento da antena $=380-390 \mu \mathrm{m}$ (Fig. 2e), de cor marrom escura, exceto o escapo, pedicelo e metade distal do $1^{\circ}$ flagelômero, amarelo, razão da proporção comprimento/largura do pedicelo do macho não ultrapassa
1,5; palpo marrom, vesícula sensorial do palpo pequena, subesférica; comprimento dos palpômeros III-V: 45; 81,5; e $111 \mu \mathrm{m}$; Proporção palpal do III ao V; 1:1,7:2,5 (Fig. 2f). Tórax: Coloração geral preta. Mesonoto enegrecido, com a luz incidindo frontalmente aparecem 1+1 manchas subtriangulares, anterodorsais, pruinosas; com luz lateral aparece mais nitidamente, uma faixa pruinosa, larga que $o$ circunda lateral e posteriormente. Mesonoto com escamas amarelo-esverdeadas. Mesepisterno, catepisterno e mesepímero enegrecido e com pruina alvacenta. Abdome: Escleritos abdominais marrom, áreas membranosas marrom, pelo basal marrom. Tergitos marrom escuros, Placa ventral mais larga que alta.

Pupa: Comprimento da pupa: 2,0-2,5 mm. Casulo chineliforme, projeção anterior pequena; trama do casulo visível. Margem anterior reforçada e mais escurecida. Comprimento dorsal do casulo: $2,0-2,5 \mathrm{~mm}$, ventral $=2,3-3,3$ $\mathrm{mm}$. Fronto-clípeo: com $2+2$ tricomas frontais simples/bífidas, longas (comprimento do tricoma ultrapassa $1 / 3$ da largura da largura do fronto-clípeo da pupa) (Fig. 3d), e 1+1 tricomas faciais bífidas, longas; fronto-clípeo com tubérculos arredondados. Comprimento da brânquia $=2,3-3,3 \mathrm{~mm}$, de comprimento igual/subigual que o comprimento da pupa. Brânquia com quatro filamentos branquiais, sendo que da base partem dois ramos primários longos, o ventral que se bifurca à aproximadamente na metade do comprimento total da branquias e o dorsal se bifurca a aproximadamente a $1 / 3$ do comprimento total da brânquia; fórmula branquial: $1[1(2)+1(2)]$ (Fig. 3k). Parte anterior do tórax com tubérculos arredondados, parte posterior com tubérculos arredondados ou subtriangulares; $5+5$ tricomas centro-toráxicos simples/bífidos / trífidos (Fig. 3g) e 1+1 par de tricomas supra-laterais simples, $3+3$ tricomas simples. Abdome: Como em S. damascenoi.

Larva: Comprimento $=3,4-4,1 \mathrm{~mm}$. Máxima largura da cápsula cefálica $=0,37-0,43 \mathrm{~mm}$. Cápsula cefálica, regiões toráxicas e abdominais com setas simples ou bífidas. Contorno do corpo apresentando protuberâncias subtriangulares dorsais que aumentam de tamanho no sentido antero-posterior, nos segmentos abdominais de II-V,2 +2 nos segmentos II-V e $1+1$ no segmento VI, e sem apresentar nenhuma no segmento VII ou VIII; $1+1$ tubérculos ventrais posteriores grandes e subtriangulares, $1+1$ tubérculos posteriores laterais reduzidos e arredondados. Apódema cefálico castanho claro com setas simples/bífidas, abundantes (Fig. 4b). Manchas na cabeça positivas. Antenas ultrapassando os ápices das hastes dos leques cefálicos. Terceiro segmento antenal mais escuro que os anteriores e com segmentos de tamanho subiguais; proporção entre os segmentos antenais I/II/III = 1: 0,95-1,24:0,8-1,10 (Fig. 4f). Leques cefálicos com 31-36 raios, comprimento do raio = $743 \mu \mathrm{m}$ (medidas tomadas nos raios do centro do leque). Escleritos cervicais pequenos, elipsóides e livres na membrana. Hipostômio com 4-7+4-7 setas laterais e 2-3+2-3 setas pequenas no disco; e 5-11+5-11 serrilhas (Fig. 7h). Fenda gular profunda e submitral; proporção entre hipostômio / ponte gular / fenda gular: 1:0,31-0,35:3-3,5 (Fig. 7d). Mandíbula com um PLM, simples, sinuoso, e ultrapassando a margem inferior da 


\section{ACTA AMAZONICA}

SIMULIIDAE (DIPTERA:CULICOMORPHA) NO BRASIL

XI - Shelleyellum GÊNERO NOVO mandíbula; três dentes pré-apicais, o terceiro dente menor que o segundo, que podem ser sub-iguais e ambos menores que o primeiro, pode haver variação no número de dentes pré-apicais, de 2 a 4; 7 a 10 dentes internos; segundo dente marginal presente, menor que o primeiro, podendo ser curvado, emergindo aparentemente de uma projeção lamelar da base do primeiro dente marginal (Fig. 8d). Esclerito anal com os braços anteriores mais curtos que os posteriores, associados com setas de pontas simples a múltiplas, bem esclerotizadas. Disco anal com 63-66 fileiras de ganchos, com 9-13 ganchos por fileira. Lobos anais com 11-16 lóbulos digitiformes em cada lobo.

Tipos e Material examinado: Holótipos e parátipos depositados na Coleção de Invertebrados do INPA (Simulídeos); Manaus, Amazonas. Rondônia: Bacia do rio Guaporé, igarapé da cachoeira, rodovia RO-399 (Vilhena / Colorado), 1 larva (no álcool) - INPA-5851, 14.vi.1981, V. PyDaniel leg.; Mato grosso: Bacia do rio Guaporé, Córrego Bacurizal, rodovia BR-364 (Km 571), no trecho Pontes de Lacerda /Vilhena (RO), 1 fêmea + respectiva exúvia pupal (6105-1) em lâmina-HOLÓTIPO, uma fêmea + respectiva exúvia pupal (61052) em lâmina - PARÁTIPO, uma larva e uma pupa (no álcool)INPA-6105, 02.x.1984, V. Py-Daniel \& Ulysses, C. Barbosa leg.; Córrego das Flexas, Bacia do rio Cuiabá, rodovia BR-070, trecho Cuiabá / Cáceres, duas pupas e 24 larvas (no álcool) - INPA6106, 05.x.1984, V. Py-Daniel \& Ulysses C. Barbosa leg.; Córrego Água Suja, Bacia do rio Cuiabá, rodovia MT-248, localidade Água Suja, 1 exúvia pupal em lâmina, INPA-6107, 29.ix.1984, V. PyDaniel \& Ulysses C. Barbosa leg.; rio Guaporé, localidade Pontes e Lacerda, rodovia BR-364, três larvas em lâmina (6108-1,2 e 3) - PARÁTIPO seis pupas e 86 larvas (no álcool) - INPA-6108, 03.x.1984, V. Py-Daniel \& Ulysses C. Barbosa leg.; Ribeirão Seixas, Bacia do rio Guaporé, rodovia BR-364 (Km 496), trecho Pontes e Lacerda / Vilhena (RO), uma pupa e 38 larvas (no álcool) INPA-6110, 03.x.1984, V. Py-Daniel \& Ulysses C. Barbosa leg.; Rio Papagaio, Bacia do rio Guaporé, rodovia BR-364 (Km 555), trecho Pontes e Lacerda / Vilhena (RO), 1 macho + respectiva exúvia pupal em lâmina (6111-1) - PARÁTIPO, três larvas em lâmina (6111-2,3 e4)- PARÁTIPOS uma exúvia pupal em lâmina (6111), 53 larvas e 22 pupas (no álcool)-INPA-6111, 03.x.1984, V. Py-Daniel \& Ulysses C. Barbosa leg.; Córrego do Bagres, bacia do rio Cuiabá, rodovia MT-388, local denominado de "Posto Fiscal para Jaurú", três pupas e sete larvas (no álcool) - INPA6112, 30.ix.1984, V. Py-Daniel \& Ulysses C. Barbosa leg.; Rio Novo, bacia do rio Guaporé, rodovia BR-364, trecho entre pontes e Lacerda/Vilhena (RO), $2003 \mathrm{Km}$ distante de Vilhena, sete larvas (no álcool)-INPA-6113, 02.x.1984, V. Py-Daniel \& Ulysses C. Barbosa leg.; Córrego Sem Nome, bacia do rio Guaporé, rodovia BR-364, trecho pontes e Lacerda Vilhena (RO), $25 \mathrm{Km}$ depois da ponte sobre o rio Guaporé, duas exúvias pupais em lâmina (6118), oito larvas (no álcoo) - INPA-6118, 03.x.1984, , V. Py-Daniel \& Ulysses C. Barbosa leg.; Rio Sararé, bacia do rio Guaporé, rodovia BR-364, trecho Pontes de Lacerda / Vilhena (RO), $61 \mathrm{Km}$ depois da ponte sobre o rio Guaporé, duas larvas e uma pupa (no álcool)-INPA-6119, 03.x.1984, V. PyDaniel \& Ulysses C. Barbosa leg.
Bionomia: Imaturos coletados em igarapés na beira de estrada, com alterações ambientais de cobertura vegetal. Larvas e pupas coletadas em folhas caídas e vegetação ciliar.

Distribuição: Rondônia (bacia do rio Guaporé, igarapé da Cachoeira, rodovia O-399, Vilhena/Colorado); Mato Grosso (Bacia do rio Guaporé: córrego Bacurizal, rodovia BR-364, Km 571, Pontes de Lacerda/Vilhena; Rio Guaporé, localidade Pontes de Lacerda, rodovia BR 364; Ribeirão Seixas, rodovia BR-364, $\mathrm{Km} 496$, Pontes de Lacerda/Vilhena; Rio Papagaio, rodovia BR$364, \mathrm{Km} 555$, Pontes de Lacerda/Vilhena; Rio Novo, rodovia BR-364, Pontes de Lacerda/Vilhena; Rio Sararé, rodovia BR-364, Pontes de Lacerda/Vilhena. Bacia do rio Cuiabá: córrego das Flexas, rodovia BR-070, Cuiabá/Cáceres; córrego Àgua Suja, rodovia MT-248, localidade Água Suja; Córrego do Bagres, rodovia MT-388). A distribuição da espécie é apresentada na Figura 9e.

\section{Shelleyellum tergospinosum comb. nov.}

\section{Simulium (Psaroniocompsa) tergospinosum Hamada, 2000}

(com base na descrição original)

Descrição: Como não foi possível ter acesso aos tipos de $S$. tergospinosum, a descrição que se segue foi retirada de Hamada (2000), usando a nomenclatura para as estruturas de genitália e larvais de Py-Daniel (1990).

Macho: Comprimento do corpo: 1,3-1,9 $\mathrm{mm}$. Comprimento lateral do corpo: 0,48-0,5 mm. Comprimento da asa: $1,7 \mathrm{~mm}$; largura: $0,8 \mathrm{~mm}$; coloração geral preta. Cabeça: Fronte, clípeo e área occipital com pruinosidade azul-prata. Pedicelo e escapo amarelo-marrom, flagelo marrom escuro. Comprimento da antena: 0,41-0,47 mm. Razão da proporção comprimento/largura do segundo segmento antenal do macho não ultrapassa 1,5 (razão medida pela figura em Hamada, 2000) (Fig. 5r). Palpo marrom escuro, II e IV palpômeros de tamanhos subiguais (IV palpômero ligeiramente maior que o III), V palpômero quase duas vezes maior que o III e IV. Vesícula sensorial pequena, subesférica. Tórax: Mesonoto preto com pelos avermelhados dourados distribuídos irregularmente, um par de bandas cuneiformes submedianas. Escutelo marrom. Anepisterno e catepisterno marrom escuros. Veias das asas marrom amarelado, espinhos e setas marrom. Halteres com a região basal marrom escura e a região terminal branqueada. Perna anterior com coxa, trocanter, fêmur e tíbia marrom amarelado pálido, todos os segmentos tarsais pretos. Perna média com coxa, trocanter, fêmur e tíbia marrom claros e todos os segmentos tarsais marrons amarelados claro. Perna posterior com fêmur, tíbia e o tarsômero $\mathrm{V}$ marrom claro distalmente e marrom escuro apicalmente; outros segmentos tarsais marrons claros. Abdome: Tergitos abdominais escuros; tergitos V-VIII com pruinosidade formando banda lateral. Esclerito mediano sub-oval com uma concavidade pequena mediana,

Fêmea: Coloração geral preta. Comprimento do corpo: 1,5-1,8 $\mathrm{mm}$. Comprimento lateral do tórax: 0,62-0,71 $\mathrm{mm}$. Comprimento da asa: $1,71-1,78 \mathrm{~mm}$. Fronte, clípeo e região occipital com pruinosidade prata azulada; fronte mais alta que 
larga (índice frontal $=1,25$, medida pelo desenho de Hamada, 2000). Comprimento da antena $460-520 \mu \mathrm{m}$ ), maior que a do macho, com pubescência prata; pedicelo, escapo e $1^{\circ}$ flagelômero amarelo claro, flagelômero seguintes marrom escuro. Palpo maxilar marrom, vesícula sensorial pequena. Palpômero V 2,1 vezes maior que o comprimento do palpômero II e 1,7 vezes maior que o IV. Mandíbula com 22-27 dentes na borda interna e 4-8 dentes na borda externa. Tórax: Mesonoto negro com pelos finos vermelhos-dourados, duas faixas prateadas. Escutelo marrom. Veias Sc e a base de R sem pêlos. Pernas de mesma cor do macho. Abdome: Escleritos abdominais marrons, áreas membranosas esverdeadas. Tergito II com pruinosidade prata azulada; tergitos VI-VIII com uma aparência envernizada.

Pupa: Comprimento da pupa: $1,8-2 \mathrm{~mm}$. Casulo chineliforme, sem projeção anterior; trama do casulo visível. Margem anterior reforçada. Comprimento dorsal do casulo: $2,3 \mathrm{~mm}$ e ventral $8 \mathrm{~mm}$. Fronto-clípeo com $2+2$ tricomas frontais simples, curtos (comprimento do tricoma não ultrapassa 1/3 da largura da largura do fronto-clípeo da pupa), e 1+1 tricomas faciais bífidos ou trífidos; fronto-clípeo sem tubérculos definidos. Comprimento da brânquia $=2 \mathrm{~mm}$ igual $/$ subigual ao comprimento da pupa. Branquia com quatro filamentos branquiais, dois ramos primários bifurcando-se logo na base, bifurcação do ramo ventral um pouco mais longo que o ramo dorsal. Fórmula branquial: $1[1(2)+1(2)]$. Parte anterior do tórax sem tubérculos, parte posterior com tubérculos arredondados ou subtriangulares; $5+5$ tricomas centrotoráxicos simples/quadrífidos e $1+1$ par de tricomas supralaterais simples/trífidos. Abdome: Segue descrição da quetotaxia do abdome com base na figura em Hamada (2000). Tergito I com $1+1$ setas filiformes, fronto-laterais. Tergito II com $5+5$ setas filiformes (a figura mostra mais $2+2$ setas, mais laterais, provavelmente são setas pleurais). Tergitos I-IV sem dentículos anteriores. Tergitos III-IV com $4+4$ ganchos simples na região posterior $1+1$ setas filiformes, transversais, frontais ao espaço entre ganchos mais externos (o desenho mostra mais $2+2$ setas, mais laterais, provavelmente são setas pleurais). Tergito $\mathrm{V}$ com $2+2$ setas filiformes, simples, no terço anterior. Tergitos VI-IX com 1+1 áreas anteriores apresentando dentículos, sem setas aparentes. Esternitos III-VI com 1+1 áreas com dentículos em forma de pente, esternito VII sem dentículos, esternito VIII com dentículos. Esternito IV com 3+3 setas, simples, externas ao 1+1 ganchos bífidos e/ou trífidos, com área membranosa longitudinal entre os ganchos e as setas. Segmento V com $2+2$ ganchos bífidos com dentículos anterolaterais. Segmentos externais VI-VII com $2+2$ ganchos (os externos simples, os internos quadrífidos), esternito VIII com $2+2$ setas simples látero-medianas.

Larva: Comprimento do último estádio: 4,3-4,6 mm. Largura máxima da cápsula cefálica: $0,31 \mathrm{~mm}$, com setas simples e pequenas. Escleritos cervicais pequenas, elípticas, livres na membrana. Fenda gular semi-circular. Ponte gular com aproximadamente metade do comprimento do hipostômio. Leque cefálico primário com 34-36 raios. Antena mais longa que a haste do leque cefálico, de proporção entre os segmentos subiguais (1:0,8-1,2:1-1,1, do segmento proximal ao distal, excluída a sensila do segmento III). Hipostômio com o dente central de mesma altura que os dentes ponta, $\operatorname{com} 2+2$ dentes laterais, $4-7$ serrilhas $+4-7$ serrilhas. $4-5+4-5$ setas hipostomais laterais. Mandíbula com 1 ou 2 PLMs, simples ou bífidos. Dentes internos da mandíbula com oito ou nove dentes internos; segundo dente marginal presente, menor que o primeiro. Corpo recoberto por setas de pontas múltiplas, dois pares de tubérculos triangulares, um dorsal e um lateral nos segmentos abdominais II ao VII; um par de tubérculos triangulares no segmento VII. Tubérculos posteriores ventrais abdominais presentes. Esclerito anal com os braços anteriores mais curto que os posteriores, associados com setas de pontas múltiplas. Disco anal com 62-69 fileiras de ganchos, com 12-15 ganchos por fileira. Lobos anais com 8-11 lóbulos digitiformes em cada lobo.

Tipos e localidade Tipo: Holótipos e parátipos depositados na coleção de Hamada, pesquisadora do INPA; Manaus, Amazonas; Clemson University Artrhopod Collection, Clemson University, SC, EUA; e Natural History Museum, Londres, Inglaterra. Localidade tipo: Cachoeira Apuí, rio Juma, Município de Apuí $\left(07^{\circ} 12^{\prime} \mathrm{S}, 59^{\circ} 54^{\prime} \mathrm{W}\right)$, Amazonas Brasil. Outras localidades além do rio Juma: Igarapé Seringueira, Município Apuí, Amazonas, Brasil. A distribuição para a espécie é mostrada na figura 9d.

Bionomia: Fêmeas são antropófilas. Larvas e pupas usam folhas caídas como substrato e também em folhas de plantas aquáticas Podostemaceae.

\section{Chave de identificação para pupas das espécies de Shelleyellum nov. gen.}

1. Número de filamentos branquiais terminais igual a 4 .........2

- Número de filamentos branquiais terminais igual a 6 , tubérculos no fronto-clípeo arredondados entremeados com triangulares; esternito IV sem ganchos; ausência de dentículos no tergito $\mathrm{V}$. ...S. guaporense

2(1). Filamentos branquiais de comprimento maior ou subiguais ao comprimento do corpo da pupa ou do casulo, tricomas do fronto-clípeo longos, podendo ser simples ou bífidas, região anterior do tórax com tubérculos arredondados.......3

- Filamentos branquiais nitidamente mais curtos que o comprimento do corpo, tricomas do fronto-clípeo curtos, simples, região anterior do tórax sem tubérculos ou esparsos.

3(2). Filamentos branquiais nitidamente maiores que o corpo da pupa, proporção: 1,23 1,35, membranas abdominais sem áreas esclerotizadas.. S. lourencoi

- Filamentos branquiais de mesmo tamanho ou subiguais ao comprimento da pupa, membranas abdominais sem áreas esclerotizadas. S. siolii

4(3). Tergitos abdominais com dentículos.........S. damascenoi - Tergitos abdominais sem dentículos......S. tergospinosum 


\section{ACTA AMAZONICA}

SIMULIIDAE (DIPTERA:CULICOMORPHA) NO BRASIL

XI - Shelleyellum GÊNERO NOVO

\section{Chave de identificação para larvas das espécies de Shelleyellum nov. gen.}

1. Tubérculos abdominais posteriores ventrais presentes, tubérculos no tergito abdominal VIII ausentes

- Tubérculos abdominais posteriores ausentes, tubérculos no tergito abdominal abdominal VIII presentes (histoblasto branquial quando dissecado ramificando-se próximo da base com 4 filamentos branquiais terminais).........S. damascenoi

2(1). Presença tubérculos no tergito abdominal I, segmento antenal IIII cerca de 1/3 maior que os segmentos I e II; (79 fileiras de ganchos no disco anal, (histoblasto branquial quando dissecado com ramificações secundárias na parte distal da branquia, 6 filamentos branquiais)......S. guaporense

- Ausência de tubérculos no tergito pupal I, segmento antenal III igual ou subigual ao I e II ou menor que o II ou menor

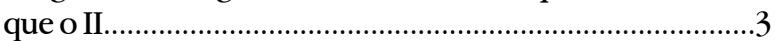

3(2). Segmentos antenais tendendo a isometria.....................

- Segmento antenal II mais longo que o III (proporção segmentos II/III: 1,2-1,3); (histoblasto branquial quando dissecado com filamentos se bifurcando mais distalmente, $\mathrm{e}$ com 4 filamentos branquiais terminais)............... S. lourencoi

4(3). Setas do apódema cefálico em número reduzido, hialinas, histoblasto branquial, quando dissecado, possui filamentos branquiais secundários se ramificando próximos da base. S. tergospinosum

- Setas do apódema cefálico grossas, abundantes, histoblasto branquial, quando dissecado, possui filamentos branquiais secundários se ramificando mais distalmente da base...S. siolii

\section{AGRADECIMENTOS}

Aos pesquisadores da CPL\&MD FIOCRUZ-AM, Sérgio Luz, pela permissão e acesso ao sistema digital de imagens; e Cláudia Rios-Velásquez pela obtenção das imagens. $\mathrm{O} 2^{\circ}$ autor agradece ao CNPq pela bolsa de doutorado.

\section{BIBLIOGRAFIA CITADA}

Adler,P.H.; Currie,D.C. ;Wood,D.M. 2004. The Black Flies (Simuliidae) of North America. Cornell University Press / Royal Ontário Museum, NY, 941 pp.

Coscarón, S. 1987. El gênero Simulium Latreille en la region Neotropical: Análisis de los grupos supraespecíficos, espécies que los integran y distribución geográfica (Simuliidae, Diptera). Museu Paraense Emílio Goeldi, Coleção Emilie Snethlage, MCT-CNPq, Belém, 111pp.

Coscarón, S.; Coscarón-Arias, C.L. 1997. Cladistic analysis of the subgenera Inaequelium, Psaroniocompsa, and Cbirostilbia of the genus Simulium, with comments on their distribution (Diptera:Simuliidae). Rev.Soc.Entomol. Argent. 56(1-4): 109-121.

Coscarón, S.; Wygodzinsky, P. 1984. Notas sobre simúlidos neotropicales VII. Sobre los subgéneros Psaroniocompsa
Enderlein y Inaequalium, subgen. Nov. Arquivos de Zoologia 31(2): 37 - 103

Coscarón, S.; Ibáñez-Bernal,S.; Coscarón-Arias, C. 1999. Revision of Simulium (Simulium) in the Neotropical Realm (Insecta:Diptera:Simuliidae). Memoirs on Entomology International, 14: 533-604.

Crosskey, R.W.; Howard,T. M. 1997. A New Taxonomic and geographical Inventory of World Blackflies (Diptera: Simuliidae). The natural History Museum, Londres, 144pp.

Crosskey, R.W.; Howard,T. M. 2004. A revised taxonomic and geographical Inventory of World Blackflies (Diptera: Simuliidae). The natural History Museum, Londres, $82 \mathrm{pp}$.

Hamada, N. 2000. "Simulium (Psaroniocompsa) tergospinosum new species (Diptera: Simuliidae) in siolii group from the southern part of the state of Amazonas, Brazil." Mem. Inst. Oswaldo Cruz 95(6): 819-828.

Hamada, N.; Azevedo, C.A. 2002. Descrição do macho e fêmea de Simulium lourencoi e lista de espécies de Simuliidae (Diptera: Nematocera) de Carolina e municípios arredores, Maranhão, Brasil. Livro de resumos do $19^{\circ}$ Congresso Brasileiro de Entomologia, Manaus, AM, 232-233

Hamada, N.; Ale-Rocha, R.; Luz, S. L. B. 2003. Description of Simulium damascenoi (Diptera: Simuliidae) male and the black-fly species from the state of Amapá, Brazil. Mem. Inst. Oswaldo Cruz 98(3): 353-360.

Palmer, R.W.; Craig, D.A. 2000. Na ecological classification of primary labral fans of filter-feeding black fly (Diptera: Simuliidae) Canadian Journal of Zoology, 78: 199-218

Pessoa, F.A.C. 2004. Revisão e análise cladística dos gêneros Cerqueirellum (Py-Daniel, 1983) $e$ Coscaroniellum (PyDaniel, 1983) Tese de Doutorado, Instituto Nacional de Pesquisas da Amazônia, 329pp

Py-Daniel, V. 1983. Caracterização de dois novos subgêneros em Simuliidae (Diptera: Culicomorpha) Neotropical. Amazoniana, 2: 159-223.

Py-Daniel, V. 1988. Simuliidae (Diptera: Culicomorpha) no Brasil VI. Sobre Simulium (Psaroniocompsa) siolii sp.n., Simulium (P.) lourencoi sp.n. e Simulium (P.) damascenoi sp.n. Rev. Saúde Púb. 22: 292-310

Py-Daniel, V. 1989. Simuliidae (Diptera:Culicomorpha) no Brasil. X-Descrição de Simulium (Psaroniocompsa) guaporense sp. N. Ver. Saúde Pub. 23: 502-508.

Py-Daniel, V.; Moreira Sampaio, R.T. 1994. Jalacimgomyia gen. N. (Culicomorpha); a ressurreição de Gymnopaidinae; a eliminação do nível tribal; apresentação de novos caracteres e a redescrição dos estádios larval e pupal de Simulium colombaschense (Fabricius, 1787) (Diptera: Simuliidae). Memórias del CAICET 4(1,2) 101-148.

\section{RECEBIDO EM 31/03/2005 ACEITO EM 18/10/2005}


